in vivo $30: 733-738(2016)$

doi:10.21873/invivo.10988

Review

\title{
The Correction of Aphakia Using Anterior Chamber Intraocular Lens
}

\author{
MARILITA M. MOSCHOS and EIRINI NITODA \\ First Department of Ophthalmology, G. Gennimatas General Hospital of Athens, \\ National \& Kapodistrian University of Athens, Athens, Greece
}

\begin{abstract}
Senile cataract is the leading cause of severe vision loss and blindness worldwide, affecting approximately 20 million people. Anterior chamber intraocular lens (AC IOLs) remain a surgical option for visual rehabilitation required after surgical extraction of the cataract lens. Relevant publications in the PUBMED database were searched for articles regarding the types, visual outcomes and the complications followed the surgical implantation of AC IOLs. AC IOLs, which can be iris- (iris-claw) or anglesupported, increase visual acuity in most patients. However, complications, such as raised intraocular pressure, hyphaema, distorted pupil shape, iris pigment precipitates, endothelial cell loss, corneal oedema, neovascular glaucoma, retinal detachment and cystoid macular oedema, can unfavorably affect the surgical outcome. Although AC IOLs have been found to improve the visual acuity of patients with cataract, they have been also implicated in several complications.
\end{abstract}

The crystalline lens is a transparent biconvex structure, participating in the refractive system of the eye. Any metabolic disturbance in the lens result in localized or diffuse opacification, called a cataract (1). Senile cataract is the leading cause of severe vision loss and blindness worldwide, affecting approximately 20 million people (2-6). The visual rehabilitation required after cataract surgery is usually treated

This article is freely accessible online.

Correspondence to: Marilita M. Moschos, Associate Professor of Ophthalmology, First Department of Ophthalmology, G. Gennimatas General Hospital of Athens, National \& Kapodistrian University of Athens, 6 Ikarias Street, Ekali, 14578, Athens, Greece. Tel: +30 6944887319, Fax: +30 2104122319, e-mail: moschosmarilita@yahoo.fr

Key Words: Anterior chamber intraocular lens, aphakia, cataract extraction, complications, visual rehabilitation, review. with aphakic glasses, contact lenses, and intraocular lenses (IOLs), which can be placed in the anterior or posterior chamber (7). The use of anterior chamber IOLs (AC IOLs) for the correction of aphakia was first reported in the 1960s (8, 9). However, this method was abandoned for about 20 years due to the high incidence of complications and the progression of cataract surgery (10). In 1996, AC IOLs were implanted in $1.09 \%$ of patients who underwent cataract extractions; this percentage had increased to $43 \%$ by 2000 (11). Since the development of AC IOLs, their design has been frequently modified, ultimately changing from a biconcave form to a convex-concave one $(12,13)$. The latter is designed to protect the corneal endothelium, which is usually vulnerable to lensinduced damage. The indications for the use of AC IOLs include extracapsular cataract extraction with intraoperative complications, intracapsular cataract extraction, secondary implantation and penetrating keratoplasty (11).

To our knowledge, this is the first article focusing on aphakic AC IOLs, and reviewing their visual outcome and complications.

\section{Outcomes and Complications Following Implantation of AC IOLs in Aphakia}

AC IOLs can be iris-(iris-claw) or angle-supported. The angle-supported IOL is fixed with four haptic points in the anterior chamber, while the iris-fixed IOL is trapped in the anterior iris surface (14). The Worst-Fechner lens (Artisan), which was developed in 2004 and approved by the US Food and Drug Administration, remains a widely used type of AC IOL (15). AC IOLs also include the retropupillary fixated Artisan, foldable acrylic IOLs, the angle-supported Kelman Multiflex (ALCON, Hemel Hempstead, UK) and other open-loop AC IOLs.

Artisan iris-claw AC IOLs. The Artisan lens (Artisan IOLS, Ophtec BV) was first introduced in the 1970s to correct aphakia (16). It is $8.5 \mathrm{~mm}$ in length, and the central 5-mm 
optic is supported by two unique flexible haptic 'claws' for iris fixation. It is a polymethylmethacrylate (PMMA) lens available in refractive powers ranging from $2 \mathrm{D}$ to $30 \mathrm{D}$ in 1-D increments, and from 14.5 $\mathrm{D}$ to $24.5 \mathrm{D}$ in $0.5-\mathrm{D}$ increments. It is fixed to the mid-peripheral iris and centered over the pupil, protecting the function of mydriasis, iris vasculature and the delicate structures of the angle. The support of the lens requires no sutures but sufficient iris tissue;suture pupilloplasty may be employed if needed to reform the pupil, and the IOL may be placed in any axis desired. The phakic platform of Artisan is marketed as Verisyse and exhibits difference in sizing from the Artisan aphakic model. The phakic Verisyse models are available in the following sizes: $7.5 \mathrm{~mm}$ with a $5-\mathrm{mm}$ optic $(-3 \mathrm{D}$ to $-23.5 \mathrm{D}$, in $0.5-\mathrm{D}$ increments), $8 \mathrm{~mm}$ with a $5-\mathrm{mm}$ optic ( $-1 \mathrm{D}$ to $-23.5 \mathrm{D}$, in $0.5-\mathrm{D}$ increments), and $8 \mathrm{~mm}$ with a 6-mm optic ( -1 to -15.5 , in 0.5 -D increments) (17).

A comparative study of AC and retropupillary implantation of iris-claw IOLs (Artisan) revealed a notable improvement of visual acuity in both aphakic groups. The prevalence of pupillary irregularity was similar (3\% and 5\%, respectively) in both groups, while a significant and temporary increase in intraocular pressure was also observed. The results were not significantly different between the two fixation techniques for iris-claw lens (18). Similarly, Teng et al. determined no statistically significant difference in endothelial cell loss following iris claw (Artisan) or posterior chamber IOLs (PC IOLs) at 3 months, 6 months and 1 year after surgery. Moreover, they revealed that the best corrected visual acuity (BCVA) was higher in the iris-claw lens group (mean $=0.40$, $\mathrm{SD}=0.12-0.80$ ) compared to the PC IOLs (mean $=0.30$, $\mathrm{SD}=0.08-0.60$ ), whereas the intraocular pressure (IOP) was much lower in the latter $(11.63 \pm 2.29 \mathrm{mmHg})$ compared to the former $(13.61 \pm 3.37 \mathrm{mmHg})$ at 1 day after surgery. No differences in BCVA and IOP were observed at 1 month and 3 months after surgery between the two groups. The postoperative complications of group one were anterior uveitis, iris depigmentation, pupillary distortion and spontaneous lens dislocation. Patients in the PC lens group experienced choroidal detachment, intraocular haemorrhage, IOLs decentration and retinal detachment $(19,20)$.

The promising visual outcome of iris-claw IOLs (Artisan IOLS, Ophtec BV) was also defined in 128 aphakic eyes lacking capsular support. The BCVA was improved 1 year postoperatively (0.52 $\log$ MAR from $0.67 \log$ MAR) and remained stable for up to 5 years. The mean endothelial cells density decreased slightly over the years. Pupillary block, transient increase in intraocular pressure, IOL replacement, penetrating keratoplasty and cystoid macular oedema were the referred complications of the implantation (21). Kheirkhah et al. also proposed iris-claw Artisan IOLs for the correction of aphakia in Fuchs' heterochromic iridocyclitis. A patient with Fuchs' heterochromic iridocyclitis achieved a
BCVA of 20/20 one month postoperatively, although a few deposits on the IOL surface were noted. The IOL remained stable with no subsequent iris atrophy, subluxation, or pupil ovalization, and glaucoma, vitreous inflammation, or clinical cystoid macular oedema were not observed (22). Li et al. observed that combined coreoplasty and Artisan IOL implantation in post-traumatic vitrectomized aphakic eyes enhanced the visual acuity of the patients without significantly affecting IOP (23).

Chen et al. performed a cohort study to assess the efficacy and safety of secondary anterior iris fixation of the Artisan iris-fixed IOL to correct aphakia in eyes lacking capsule support. They recruited 72 patients who were followed-up for 3 years. The visual acuity was improved in all patients, except for two who experienced postoperative ischaemic optic neuropathy or retinal detachment. The mean postoperative IOP was not significantly increased throughout the follow-up, whereas the mean rate of endothelia loss was $9.78 \%$. The observed complications included glare and halos during night driving $(16.7 \%)$ and iris pigment precipitates $(5.6 \%)(24)$.

The outcome of intraocular implantation of an iris-claw aphakic IOL during primary lens surgery or following a dislocated PC IOL or as a secondary procedure was studied in 116 eyes for a period of around 22.4 months. The visual acuity was $6 / 12$ or better in $69 \%$ of the eyes, whereas the referred complications included postoperative increase in intraocular pressure $(9.5 \%)$, cystoid macular oedema $(7.7 \%)$, iris-claw IOL subluxation $(6.0 \%)$, wound leak requiring resuturing $(2.6 \%)$, corneal decompensation $(1.7 \%)$ and retinal detachment $(0.8 \%)$ (25). Cagini et al. supported that simultaneous keratoplasty (Descemet's stripping automated endothelial keratoplasty, DSAEK) and aphakic iris-fixated IOL implantation in patients with aphakia and bullous keratopathy was safe, resulting in stable IOL without referred postoperative complications (26). Similarly, Koss and Kohnen ascertained that the loss of corneal endothelial cells was not significant in 18 aphakic eyes which received AC iris-claw lenses. The rate of loss was negatively correlated with the axial length, being negligible for eyes with axial length of $24 \mathrm{~mm}$ or more (27).

The use of Artisan-Verysise intraocular lens for secondary implantation and correction of aphakia has been estimated to be safe, also achieving a BCVA of $20 / 40$ or better in $37.5 \%$ of eyes treated by Güell et al.; corneal endothelial cell loss was mainly observed within the first year (7.78\%), whereas cystoid macular oedema was diagnosed in two out of a total of 16 patients in a follow-up of at least 3 years (28). A customized PMMA iris print and iris-clipped AC IOL (Ophtec BV) has been proposed to repair aniridia along with correction of aphakia and corneal astigmatism (29). The vertical placement of an aphakic Artisan (Ophtec) IOL in the anterior chamber of a patient who had a perforating injury 
to the cornea led to a BCVA of 0.93 months later without complications. Traumatic aniridia was the cause for the vertical location of the lens (29).

Open-loop AC IOLs. The fixation of open-looped AC IOLs to the iris has been suggested as surgical approach for correcting the instability of such IOLs and subsequent progressive corneal damage (30). Dai et al. noted the causes of a flexible open-loop anterior chamber IOL extraction in 28 eyes which kept the lenses for a mean of 6 years. They found that bullous keratopathy was the most common cause, accounting for $42.9 \%$ of the eyes, followed by secondary glaucoma $(32.1 \%)$, retinal detachment $(17.9 \%)$ and lens dislocation $7.1 \%$ (31). An earlier study comprised 18 patients (20 aphakic eyes) who had secondary flexible, open-loop (Coburn $120 \mathrm{UV}^{\circledR}$ ) AC IOL implantation, detecting no visual deterioration during the follow-up (mean time 93.8 months). The observed complications included corneal decompensation (one patient), retinal detachment (one patient) and pupil distortion (five eyes). The postoperative IOP was significantly reduced (32).

Evereklioglu et al. compared surgical outcomes following the secondary implantation of a flexible, open-loop, singlepiece, PMMA AC IOL (AC260T, Ophtec, or OPAB16, Hanita) (group 1) and a flexible, open-loop (haptics with eyelets), scleral-fixated, PMMA PC IOL (CZ70BD, Alcon) (group 2) in 124 aphakic eyes with insufficient capsule support. The comparison revealed no statistically significant difference in the visual outcome between the groups. However, the visual acuity was higher in group 1. On the other hand, the referred complications following the implantation were more frequent in the AC IOL group and included early transient corneal oedema, increased IOP, cystoid macular oedema, hyphaema, secondary glaucoma, and iris capture or pupil decentralization (33).

An older study compared the surgical outcome of AC IOL implantation using open-loop lenses or closed-loop designs. Open-loop AC IOLs Ied to a significantly lower rate of complications, while closed-loop designs were related to almost $80 \%$ of corneal pathology (34). Drolsum and Haaskjold also noted that open loop AC IOLs can achieve a visual acuity of $5 / 5$ or better and a postoperative refraction within 1 diopter of emmetropia. There was only one case of cystoid macular oedema among 20 aphakic eyes (35). The combination of an open-loop AC IOL implantation with penetrating keratoplasty in patients suffering from pseudophakic or monocular aphakic bullous keratopathy had good postoperative visual outcome even in the early 1990s. The referred causes of failed visual improvement (less than 20/200) were cystoid macular oedema, glaucoma, and immunological graft failure (36).

Foldable acrylic IOLs. The use of an angular supported foldable acrylic IOL in 21 patients with unilateral aphakia revealed the improvement of visual acuity $(1.26 \pm 0.46$ $\log$ MAR pre-operatively and $0.78 \pm 0.57 \log$ MAR postoperatively, $p=0.003$ ), which can be achieved with the implantation of AC IOLs. The observed complications included intraocular hypertension (over $21 \mathrm{mmHg}$ ) in $14.3 \%$ of the patients, macular oedema $(5 \%)$, pupillar ovalization (5\%), and retinal detachment $(5 \%)$. They concluded that an angular support foldable lens in the $\mathrm{AC}$ is a useful technique for the correction of aphakia in eyes without capsular support (37). The application of a new foldable foldable acrylic AC IOL (Acri.Lyc 15A, Acritec) through a small incision has also been found to result in increased visual acuity, being accompanied by several complications. The latter include reduction in endothelial cell density, corneal oedema, Descemet folds, raised IOP, hyphaema, distorted pupil shape, 'iris bombe', blood in the vitreous, displaced IOL and cystic macular oedema. However, the authors noted that these complications had no effect on the final visual outcome (38).

Kelman Multiflex AC IOLs. Similarly, the inverted insertion of a Kelman Multiflex AC IOL in fourcases was followed by chronic iritis, cystoid macular oedema, pupil capture, iris adhesions, and corneal decompensation (39). At the Lahan Eye Hospital, Southern Nepal, 2000 people with bilateral cataracts underwent intracapsular extraction with aphakic correction or with an AC IOL implantation in their first operated eye. They used a single-piece four-point fixation (19.0 or 19.5 dioptre) CILCO Kelman Multiflex III AC IOL (ALCON). The functional visual acuity was $6 / 60$ or less in approximately $5 \%$ of the AC IOL group 1 year after surgery in comparison to $5.4 \%$ for the controls. The poor vision was attributed to uncorrected refractive error in the majority of patients, whereas it was related to surgical complications in only $2 \%$ of them. Uveitis and glaucoma were the common causes of decreased visual acuity in the AC IOL group (40).

Other studies. Similarly, Suelves et al. supported the safety and efficacy of MTA3UO AC IOLs (Alcon Laboratories, Inc.) and L122UV AC IOLs (Bausch \& Lomb) in uveitic patients with inadequate capsule support and in patients without a history of intraocular inflammation. PMMA is an acrylic biomaterial made from one type of monomer. It contains both hydrophobic (methylene) and hydrophilic (carbonyl) groups. The MTA3UO is a convex-plano openloop PMMA IOL. The L122UV is a PMMA IOL that has a vaulted equiconvex design $(41,42)$. Besides the common complications following AC IOL (MTA3UO ALCON) implantation, Farah et al. reported the fracture of such IOL after Nd:YAG laser iridotomy (43).

Air-assisted AC IOL implantation has been suggested as a safe and effective technique for implantation of theses lenses in cases with progressive lens subluxation. The mean BCVA was found to be raised 6 months postoperatively 
(from 0.67 to $0.25 \log$ MAR), with no negative effect on IOP $(14.54 \pm 1.38 \mathrm{mmHg}$ at baseline and $15.16 \pm 1.15 \mathrm{mmHg}$ at $6-$ month follow-up). The mean corneal endothelial count at 6 months was reduced $\left(2,947 \pm 194.9\right.$ cells $\left./ \mathrm{mm}^{2}\right)$ compared to that at baseline $\left(3,151 \pm 240.49\right.$ cells $\left./ \mathrm{mm}^{2}\right)(44)$. Esquenazi et al. evaluated endothelial cell survival 2 years after DSAEK in the presence of an AC IOL. They estimated that although the AC IOL was well-centered, the mean endothelial cell loss in the first and second year were $24 \%$ and $28 \%$, respectively (45). Hazar et al. compared the visual outcome and enthodelial cell loss among AC iris-fixed IOL, retropupillary iris-fixed IOL, and scleral-fixed PC IOL implantation. The visual acuity was $20 / 40$ or better in $62.9 \%, 50 \%$ and $58.1 \%$ of eyes after implantation, respectively. Although the visual improvement was higher in the AC iris-fixed IOL group, the scleral-fixed PC IOL group exhibited the lowest loss of endothelial cells (5.9\%) compared to AC iris-fixed IOL (7.2\%) and retropupillary iris-fixed IOL (11.4\%) groups (46). Ravalico et al. confirmed the corneal endothelial loss in eyes undergoing cataract surgery with primary or secondary AC IOL implantation. Moreover, they concluded that the endothelial cell difference was significantly greater in aphakic patients who had a secondary compared to primary AC IOL implantation (47).

AC IOLs have proven to be safe and useful for visual rehabilitation, when they are implanted in combination with silicone oil removal: $87.5 \%$ of eyes exhibited improved or unchanged visual acuity compared to $85.3 \%$ of eyes in which PC IOLs were used. No statistically significant differences in the incidence of complications, including corneal oedema, elevated intraocular pressure, hypotony, and retinal detachment, between the two groups were found (48). On the other hand, a clinicopathological report on Choyce Mark VIII anterior chamber IOL was made by Ollerton et al., using an enucleated eye that was blind and painful. The microscopic features revealed the presence of corneal decompensation and vascularization, the formation of peripheral anterior and posterior synechiae, significant alterations in the iris (thinning, fibrous tissue) and the development of Soemmerring ring in the remnants of the capsular bag. The IOL surface was smooth and regular, partially covered by various cells, including giant cells intermixed with pigment (49). The secondary implantation of an AC IOL seemed to attain a visual acuity of 20/40 or better in $71.4 \%$ of the eyes, compared to $92 \%$ and $57.1 \%$ of patients where PC and scleral-fixed PC lenses, respectively, were used. The same study noted that corneal endothelial cell loss and other complications, such as cystoid macular oedema, persistent fibrinous membrane formation, and neovascular glaucoma were more frequent in patients where an AC IOL was used (50).

Artaria estimated the complications followed the secondary implantation of an AC IOL of Symflex type after uneventful intracapsular cataract extraction in 45 aphakic eyes. The 40-month follow-up revealed minimal (12 cases) or advanced pupillary deformation (three cases), formation of peripheral anterior synechia (one case), pupillary block glaucoma (two cases), worsening of the BCVA (eight cases), retinal detachment (two cases) and cystoid macular oedema (one case) (51). Spirig and Jenny observed retinal detachment (two cases), cystoid macular edema (one case), corneal dystrophy, glaucoma or lens dislocations in aphakic eyes undergoing secondary implantations of AC IOLs (52). Retinal detachment and bullous keratopathy are severe complications which can impair the visual outcome after AC IOL implantation (53).

\section{Conclusion}

Although AC IOLs have been found to improve visual acuity, they have been also implicated in several complications, including loss of corneal endothelial cells and corneal decompensation, increase in IOP, pupillary distortion, cystoid macular oedema and retinal detachment.

\section{Conflicts of Interest}

None of the Authors has any conflict of interest to declare and no financial support was offered for the present review. The Authors alone are responsible for the content and writing of this article.

\section{References}

1 Snell R and Lemp M: Clinical anatomy of the eye. 2nd edition. Blackwell Science., Inc. 2006.

2 www.who.int/blindness/causes/priority/en/index1.html.

3 Zheng Y, Lavanya R, Wu R, Wong WL, Wang JJ, Mitchell P, Cheung N, Cajucom-Uy H, Lamoureux E, Aung T, Saw SM and Wong TY: Prevalence and causes of visual impairment and blindness in an urban Indian population: the Singapore Indian eye study. Ophthalmology 118: 1798-1804, 2011.

4 Zhao J, Ellwein LB, Cui H, Ge J, Guan H, Lv J, Ma X, Yin J, Yin ZQ, Yuan Y and Liu: Prevalence of vision impairment in older adults in rural China: the China Nine-Province Survey. Ophthalmology 117: 409-416, 2010.

5 Hyman L, Wu SY, Connell AM, Schachat A, Nemesure B, Hennis A and Leske MC: Prevalence and causes of visual impairment in The Barbados Eye Study. Ophthalmology 108: 1751-1756, 2001.

6 Varma R, Ying-Lai M, Klein R and Azen SP: Prevalence and risk indicators of visual impairment and blindness in Latinos: the Los Angeles Latino Eye Study. Ophthalmology 111: 11321140, 2004.

7 Laroche L: Actuality in cataract treatment. Rev Prat 63: 43-47, 2013. French.

8 Emmrich K: Correction of the aphakic eye with anterior chamber lenses. Dtsch Gesundheitsw 13: 353-355, 1958.

9 Strampelli B: Tolerance of acrylic lenses in the anterior chamber in aphakia and refraction disorders. Ann Ottomol Clin Ocul 80: 75-82, 1954. 
10 Cotlier E and Herman S: Aphakic flat anterior chamber. Treatment by anterior vitriotomy. Arch Ophthalmol 86: 507-516, 1971.

11 Girard A, Ellies P, Bejjani RA, Assaraf E and Renard G: Why are aphakic anterior chamber intraocular lenses still implanted? Five-year incidence and implantation circumstances at the HôtelDieu in Paris. J Fr Ophtalmol 26: 344-349, 2003.

12 Fechner PU, Haubitz I, Wichmann W and Wulff K: WorstFechner biconcave minus power phakic iris-claw lens. J Refract Surg 15: 93-105, 1999.

13 Menezo JL, Aviño JA, Cisneros A, Rodriguez-Salvador V and Martinez-Costa R: Iris claw phakic intraocular lens for high myopia. J Refract Surg 13: 545-555, 1997.

14 Kohnen T and Hengerer FH: Anterior chamber intraocular lenses for aphakia correction. Ophthalmologe 111: 310-314, 2014.

15 Maloney RK, Nguyen LH and John ME: Artisan phakic intraocular lens for myopia: short-term results of a prospective, multicenter study. Ophthalmology 109: 1631-1641, 2002.

16 Worst JG, Massaro RG and Ludwig HH: The introduction of an artificial lens into the eye using Binkhorst's technique. Ophthalmologica 164: 387-39, 1972.

17 Teichman JC and Ahmed IIK: Improved Technique with the Artisan Aphakic IOL. Rev Ophthalmol 14: 59, 2007.

18 Helvaci S, Demirduzen S and Oksuz H: Iris-claw intraocular lens implantation: Anterior chamber versus retropupillary implantation. Indian J Ophthalmol 64: 45-49, 2016.

19 Teng H, Zhang H, Tian F, Sun J and Wang T: Artisan iris claw intraocular lens implantation for the correction of aphakia after pars plana vitrectomy. Zhonghua Yan Ke Za Zhi 50: 89-94, 2014.

20 Teng $\mathrm{H}$ and Zhang $\mathrm{H}$ : Comparison of Artisan iris-claw intraocular lens implantation and posterior chamber intraocular lens sulcus fixation for aphakic eyes. Int J Ophthalmol 7: 283287, 2014.

21 Güell JL, Verdaguer P, Elies D, Gris O, Manero F, MateuFigueras G and Morral M: Secondary iris-claw anterior chamber lens implantation in patients with aphakia without capsular support. Br J Ophthalmol 98: 658-663, 2014.

22 Kheirkhah A, Nikdel M and Ghadimi H: Implantation of iris-claw Artisan intraocular lens for aphakia in Fuchs' heterochromic iridocyclitis. Indian J Ophthalmol 62: 373-374, 2014.

$23 \mathrm{Li} \mathrm{H}$, Cai J, Huang Y, Wu D, Zhang Y and Wu D: Coreoplasty and Artisan intraocular lens implantation for mydriasis and aphakic correction in post-traumatic vitrectomized eyes. Eye Sci 27: 119-123, 2012.

24 Chen Y, Liu Q, Xue C, Huang Z and Chen Y: Three-year followup of secondary anterior iris fixation of an aphakic intraocular lens to correct aphakia. J Cataract Refract Surg 38: 1595-1601, 2012.

25 De Silva SR, Arun K, Anandan M, Glover N, Patel CK and Rosen P: Iris-claw intraocular lenses to correct aphakia in the absence of capsule support. J Cataract Refract Surg 37: 1667$1672,2011$.

26 Cagini C, Fiore T, Leontiadis A, Biondi L, Leaci R, Delfini E and Macaluso C: Simultaneous Descemet stripping automated endothelial keratoplasty and aphakic iris-fixated intraocular lens implantation: a case series. Cornea 30: 1167-1169, 2011.

27 Koss MJ and Kohnen T: Intraocular architecture of secondary implanted anterior chamber iris-claw lenses in aphakic eyes evaluated with anterior segment optical coherence tomography. Br J Ophthalmol 93: 1301-1306, 2009.
28 Güell JL, Velasco F, Malecaze F, Vázquez M, Gris O and Manero F: Secondary Artisan-Verysise aphakic lens implantation. J Cataract Refract Surg 31: 2266-2271, 2005.

29 Kamburoğlu G, Bahadir M and Ertan A: Vertical placement of aphakic Artisan intraocular lens in a patient with traumatic localized aniridia. J Cataract Refract Surg 32: 1567-1569, 2006.

30 Belkin A, Ofir S, Kleinmann G, Assia E and Segev F: Iris fixation of unstable anterior chamber intraocular lenses. Cornea 34: 1573-1576, 2015.

31 Dai YH, Xie LX, Huang YS, Wu XM, Zhang H and Lan J: Analysis of patients with extraction of open-loop anterior chamber intraocular lenses. Zhonghua Yan Ke Za Zhi 47: 546-549, 2011.

32 Drolsum L: Long-term follow-up of secondary flexible, openloop, anterior chamber intraocular lenses. J Cataract Refract Surg 29: 498-503, 2003.

33 Evereklioglu C, Er H, Bekir NA, Borazan M and Zorlu F: Comparison of secondary implantation of flexible open-loop anterior chamber and scleral-fixated posterior chamber intraocular lenses. J Cataract Refract Surg 29: 301-308, 2003.

34 Auffarth GU, Wesendahl TA, Brown SJ and Apple DJ: Are there acceptable anterior chamber intraocular lenses for clinical use in the 1990s? An analysis of 4104 explanted anterior chamber intraocular lenses. Ophthalmology 101: 1913-1922, 1994.

35 Drolsum L and Haaskjold E: Secondary implantation of flexible open loop anterior chamber IOLs. Acta Ophthalmol (Copenh) 71: 482-486, 1993.

36 Zaidman GW and Goldman S: A prospective study on the implantation of anterior chamber intraocular lenses during keratoplasty for pseudophakic and aphakic bullous keratopathy. Ophthalmology 97: 757-762, 1990.

37 Giles K, Ernest M, Christelle D, Georges NT, Raoul C, Come EM and Wiedemann P. Aphakia correction by injection of foldable intra ocular lens in the anterior chamber. Ophthalmol Eye Dis 5: 17-22, 2013.

38 Omulecki W, Bartela J, Synder A, Pałenga-Pydyn D and Wilczyński M: Results of implantation a new type of foldable anterior chamber intraocular lens. Klin Oczna 113: 216-222, 2011.

39 Fintelmann RE, Kim SK and Hwang DG: Upside-down lens syndrome: ocular complications secondary to inverted implantation of the Kelman Multiflex anterior chamber intraocular lens. Am J Ophthalmol 152: 122-125, 2011.

40 Hennig A, Evans JR, Pradhan D, Johnson GJ, Pokhrel RP, Gregson RM, Hayes R, Wormald RP and Foster A: Randomised controlled trial of anterior-chamber intraocular lenses. Lancet 349: 1129-1133, 1997.

41 Suelves AM, Siddique SS, Schurko B and Foster CS: Anterior chamber intraocular lens implantation in patients with a history of chronic uveitis: five-year follow-up. J Cataract Refract Surg 40: 77-81, 2014.

42 Suelves AM, Kruh JN, Aznar-Peña I, Siddique SS and Foster CS: Long-term safety and visual outcomes of anterior chamber intraocular lens implantation in patients with a history of chronic uveitis. J Cataract Refract Surg 38: 1777-1782, 2012.

43 Farah E, Koutsandrea C, Papaefthimiou I, Papaconstantinou D and Georgalas I: Fractured Anterior Chamber Intraocular Lens (ACIOL) Complicating Nd: YAG Laser for Peripheral Iridotomy. Open Ophthalmol J 8: 1-2, 2014.

44 Agarwal T, Gupta S, Sharma N, Khokhar S and Jhanji V: Airassisted implantation of anterior chamber intraocular lens. Eye Contact Lens 41: 164-166, 2015. 
45 Esquenazi S, Schechter BA and Esquenazi K: Endothelial survival after Descemet-stripping automated endothelial keratoplasty in eyes with retained anterior chamber intraocular lenses: two-year follow-up. J Cataract Refract Surg 37: 714-719, 2011.

46 Hazar L, Kara N, Bozkurt E, Ozgurhan EB and Demirok A: Intraocular lens implantation procedures in aphakic eyes with insufficient capsular support associated with previous cataract surgery. J Refract Surg 29: 685-689, 2013.

47 Ravalico G, Botteri E and Baccara F: Long-term endothelial changes after implantation of anterior chamber intraocular lenses in cataract surgery. J Cataract Refract Surg 29: 1918-1923, 2003.

48 Zhang Y, Sun D, Zhang Z, Xiao H and Peng S: Combined silicone oil removal with secondary implantation of anterior chamber or sclera-fixed posterior chamber intraocular lenses. Eur J Ophthalmol 23: 697-704, 2013.

49 Ollerton A, Stagg BC, Leishman L, Bodnar Z, Werner L and Mamalis N: Long-term pathologic follow-up of obsolete design: Choyce Mark VIII anterior chamber intraocular lens. J Cataract Refract Surg 38: 368-372, 2012.
50 Hahn TW, Kim MS and Kim JH: Secondary intraocular lens implantation in aphakia. J Cataract Refract Surg 18: 174-179, 1992.

51 Artaria LG: Long-term results of secondary implantation of anterior chamber lenses. Klin Monbl Augenheilkd 200: 571-573, 1992.

52 Spirig $\mathrm{R}$ and Jenny GP: Experiences with secondary implantation of anterior chamber lenses. Klin Monbl Augenheilkd 200: 568-570, 1992.

53 Pojda SM, Herba E, Zatorska B, Pojda-Wilczek D and Rycerska A: The long term clinical outcome of anterior chamber lenses after cataract surgery. Klin Oczna 104: 99-103, 2002.

Received July 6, 2016

Revised July 22, 2016

Accepted August 17, 2016 